\section{QUALITY OPTIMIZATION OF} THE MACHINED SURFACE IN TERMS OF ELECTRIC ENERGY CONSUMPTION IN THE WEDM PROCESS

LUBOSLAV STRAKA, PATRIK KUCHTA

Department of Automotive and Manufacturing Technologies Faculty of Manufacturing Technologies of the Technical University of Kosice with a seat in Presov, Presov, Slovakia

DOI: 10.17973/MMSJ.2021_6_2021023 luboslav.straka@tuke.sk

Current engineering production is characterized by everincreasing requirements for the final quality of products. But high fabrication productivity is required in many cases as well. Another advantage is, of course, a beneficial economic efficiency of the production process. However, despite the advanced technical level of production and extensive knowledge in the field of electro-erosive machining, in many cases, the overall efficiency of the production process is based on the skills of operators. Besides, insufficiently experienced production operators sometimes still use the trial and error system, even today. A comprehensive set of information for selecting optimal conditions of the electric discharge machining process with the possibility of practical application in real conditions of practice is currently non-existent. The paper therefore describes the experimental measurements performed in order to optimize the quality of the machined surface with respect to electric energy consumption in the WEDM process. In contrast to current approaches, the solution of the issue relied on determining the relationship between the performance parameters of the process and its controllable output quality parameters so that they would be applicable to the conditions of real practice. It was found that with the reduction of discharge energy through individual WEDM operations, the quality indicators in terms of roughness parameters improve. However, on the other hand, reducing the discharge energy leads to a significant increase in the total electric energy consumption. Therefore, the aim of the performed optimization was to look for a suitable type of WEDM operation, in which a favourable value of the roughness of the eroded surface is achieved while maintaining favourable electric energy consumption.

KEYWORDS

Electric energy consumption, Main Technological Parameters (MTP), optimization, progressive technology, surface quality, Wire Electrical Discharge Machining (WEDM).

\section{INTRODUCTION}

The energy intensity of production technologies has become a frequently discussed topic among current researchers and experts in industrial practice. These discussions aimed to increase the overall energy efficiency of individual production processes. To this end, many studies of production processes have been carried out in order to gain relevant knowledge for a better understanding of the interrelationships between energy intensity and the resulting efficiency of the production process [Yaman 2020]. However, it is essential to know the details concerning the production process itself in the first place. In the past, all experimental research concerning the economic efficiency of the machining process was mainly focused on conventional production technologies, such as turning, milling, grinding, etc. But, detailed studies on the economic efficiency of unconventional production technologies have not yet been sufficiently compiled. One of these progressive technologies, which lacks a comprehensive database of knowledge concerning the economic efficiency of the machining process, is also WEDM. WEDM is a progressive technology that can be used to produce any shape [Meshram 2020]. The only condition for machinability is the electrical conductivity of the machined material. Since the electro-erosive process takes place in the presence of a liquid dielectric, another advantageous quality of the workpiece material is the resistance to liquid absorption. However, this is not a limiting condition. It is important to emphasize, that it is rather senseless to make products by electro-erosive machining if there is a faster and more energyefficient way to operate. Although it may not seem so, EDM is one of the more energy-intensive technologies. Hence, in practice, it is usually only used in the cases of increased demands on the machining process, or more precisely, on the achieved quality of the machined surface [Mouralova 2016]. These cases also include machining of complicated shapes or carbides [Rouniyar 2019]. These aspects led us to perform experimental measurements aiming to expand the theoretical basis regarding the economic efficiency of the application of WEDM technology. Additionally, the task was to present an empirical approach to mathematical modeling and optimization of energy efficiency in WEDM of tool steel EN 40CrMnMoS8-6 with respect to the quality of the machined surface. The experimentally obtained results also revealed the relationship between the total electricity consumption and the achieved quality of the eroded area during WEDM.

\section{THEORETICAL BASIS FOR SOLVING THE PROBLEM}

EDM is one of the progressive technologies requiring no direct contact between the workpiece and the tool, which makes it different from the traditional machining method. The removal of metal particles from the workpiece occurs through the action of electric discharges with the simultaneous action of high temperature at the point of discharge [Salcedo 2017]. Although this method of machining does not involve the mechanical removal of metal particles from the machined material, EDM is one of the more demanding technologies in terms of energy. In addition to the actual consumption of electrical energy, intended to provide discharge energy for material removal, the energy is also consumed in the control system, in the tool and workpiece movement system, and in the dielectric fluid supply system as well [Raksiri 2010]. Although in EDM the instantaneous consumption of electricity is relatively small compared to other conventional or progressive technologies, its overall balance for machining a specific area is relatively large [Antar 2011]. This is because EDM requires long machining times. For instance, cutting material using other technologies, whether conventional (angle grinder cutting) or progressive (laser or water jet cutting), requires only a fraction of the time compared to the WEDM technology [Baron 2016]. This fact is also pointed out by many experimental studies [Devarajaiah 2018]. They indicate that this is mainly due to the intensity of material removal, which is relatively small compared to other technologies [Gamage 2017]. These researchers further point to another fact, which is the low ratio of total cutting power to total electricity consumption [Gangil 2017]. This is mainly due to the fact that, in addition to the mechanical energy produced, a substantial 
part of the electrical energy is consumed for waste heat energy [Li 2015]. Although part of this heat energy is used to melt and remove metal particles from the workpiece, it is only a negligible part compared to the waste heat energy. It is the heat energy that is dissipated through the machined material, wire electrode, dielectric fluid, friction in the lines, heat loss in the windings of electric motors, etc. [Panda 2018]. As a result, this means that heat losses are a decisive factor in electricity consumption during WEDM and the evaluation of its overall economic efficiency [Wang 2014]. Another decisive criterion in assessing the economic efficiency of WEDM is the consumption of electricity, which is directly related and contributes to the provision of the EDM process [Van 2020]. Its magnitude is significantly influenced by the dimensions of the workpiece and tool electrode, their material properties, the properties of the dielectric fluid and, last but not least, the setting of the main technological parameters (MTP).

\section{ANALYSIS OF ELECTRICITY CONSUMPTION DURING WEDM}

In most cases, an EDM has a number of elements that are less energy-intensive [Zheng 2019b]. In addition to different electricity consumption, they also differ in the performed function [Michalik 2016]. Based on these two criteria, the individual elements of a standard EDM can be classified into five subsystems:

1. computer numerical control (CNC) subsystem - used to control individual components of the EDM machine and also to communicate with the operator. In terms of energy intensity, it represents a subsystem with relatively low electricity consumption, which is around $0.7 \mathrm{~kW} . \mathrm{h}^{-1}$. It is also characterized by relatively constant electricity consumption;

2. dielectric cooling and supply subsystem - provides continuous cooling, circulation, and filtration of dielectric fluid. In terms of energy intensity, it represents a subsystem with electricity consumption at the level of 1.5-6.0 kW.h-1. The electrical energy consumption in this subsystem varies according to the intensity of the purge pressure and the intensity of the cooling of the dielectric fluid;

3. servo drive subsystem - ensures the movement of the work table. In terms of energy intensity, it represents a subsystem with very low electrical energy consumption of individual components. The electricity consumption in this subsystem varies according to the number of servo drives implemented and the speed of the work table. Its value during the electroerosive process is approximately at the level of $2.0 \mathrm{~kW} \cdot \mathrm{h}^{-1}$;

4. wire electrode feeding subsystem - provides tensioning and rewinding of the wire electrode. In terms of energy intensity, it represents a subsystem whose energy consumption depends on the tensioning force of the wire electrode and the speed of its rewinding. By default, its value is $1.5 \mathrm{~kW} . \mathrm{h}^{-1}$;

5. electrical pulse generation subsystem - supplies the energy needed to provide a discharge between the workpiece and the wire electrode. In terms of energy intensity, it represents another subsystem with the highest electricity consumption after subsystem no. 2 (cooling and circulation of dielectric fluid). It depends on the intensity of discharge energy, and during electro-erosive machining, it is at the level of about 0.0 to $5.5 \mathrm{~kW} . \mathrm{h}^{-1}$.
The following Figure 1 shows the change in the total power input $P_{W E D M}$ of the electro-erosive machine during WEDM by successively connecting the individual elements of the subsystems No. 1 to 5 .

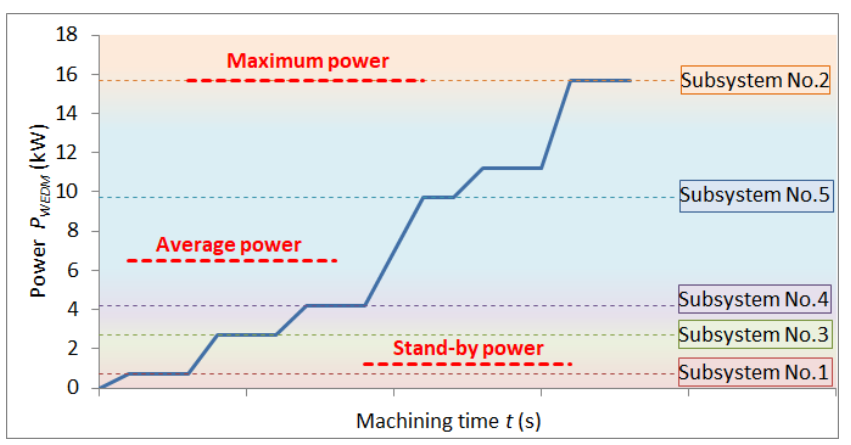

Figure 1. Total power $P_{W E D M}$ of electro-erosive machine during WEDM by the successive connection of individual elements of subsystems No. 1 to 5

As can be seen in Fig. 1, the EDM consumes a certain minimum amount of electricity even in the stand-by mode. Gradual connection of individual elements of subsystems No. 1 to 5 also increases the energy consumption of the EDM during WEDM. Maximum consumption is achieved when all elements of the electro-erosive process work at their maximum power at once [Hasova 2016]. This situation during WEDM occurs only in rare cases and for a short amount of time. A much more common case is when an EDM device consumes a certain average amount of electricity during standard WEDM operations.

\section{MATHEMATICAL MODELING OF ELECTRICITY CONSUMPTION DURING WEDM}

Mathematical modeling is an important tool for achieving an effective increase in the overall stability and efficiency of the WEDM process [Zheng 2019a]. It would be advantageous if the current mathematical modeling of the efficiency of the WEDM process also achieved favorable energy savings [Malega 2017]. In addition to mathematical modeling of electricity consumption, its optimization is also a crucial part of increasing the economic efficiency of the WEDM process [Kumar 2017]. Since at present, the biggest problem is to achieve the savings of electricity required for pulse power supply, by optimizing its operation with respect to achieving the required quality of the machined surface, we can significantly contribute to achieving higher energy efficiency, and therefore significantly reduce machining time [Ngocpi 2020]. This will also effectively reduce the overall electricity consumption during WEDM [Zhang 2017]. The total electricity consumption during WEDM can be determined using Equation (1):

$$
E_{W E D M}=E_{s u b 1}+E_{s u b 2}+E_{s u b 3}+E_{s u b 4}+E_{s u b 5}
$$

Where $E_{W E D M}$ is the total energy consumption of the EDM during WEDM, $E_{\text {sub1 } 1}$ is the energy consumption of the CNC subsystem during the WEDM, $E_{\text {sub2 }}$ is the energy consumption of the cooling and dielectric supply subsystem during the WEDM, $E_{\text {sub3 }}$ is the energy consumption of the servo-drive subsystem during the WEDM, $E_{\text {sub4 }}$ is the energy consumption of the wire electrode feeding subsystem during the WEDM and $E_{\text {sub5 }}$ is the energy consumption of the electrical pulse generation subsystem during the WEDM.

The electricity consumption by the individual subsystems of the EDM can be calculated using equations (2) to (6).

The consumed electrical energy in the CNC subsystem is used to ensure activities related to the control of individual 
components of the electro-erosive machine. Even in stand-by mode, this subsystem consumes a certain constant amount of electricity. It is a subsystem whose consumption is relatively stable and can therefore be easily described by a mathematical model (2):

$$
E_{\text {subl }}=t \cdot P_{\text {subl }}
$$

Where $t$ is the running time of the control subsystem and $P_{\text {sub1 }}$ is the power input of the control subsystem.

A slightly more complicated situation is when formulating a mathematical model describing the power consumption of the cooling and dielectric supply subsystem. It is a subsystem that circulates the dielectric fluid and adjusts its temperature if necessary. Circulation and transport of the dielectric fluid to the working space are ensured by a pump. The temperature adjustment of the dielectric fluid is performed by a cooling device. The operation of both devices depends on the current conditions of the electro-erosive process. While the fluid pump operates practically continuously during the electro-erosive machining, the cooling system is only put into operation when the temperature of the dielectric fluid needs to be adjusted. In the cases of fine finishing operations with lower discharge energy, a substantially smaller amount of heat energy is released into the dielectric fluid, and therefore, the need for cooling is considerably less compared to machining processes in which higher discharge energy is applied. The electrical energy consumption of the cooling and dielectric supply subsystem during the WEDM can be determined by this mathematical model (3):

$$
E_{s u b 2}=\left(t_{f p} \cdot P_{f p}\right)+\left(t_{c c} \cdot P_{c c}\right)
$$

Where $t_{f p}$ is the running time of the fluid pump, $P_{f p}$ is the power input of the fluid pump, $t_{c c}$ is the running time of the cooling circuit and $P_{c c}$ is the power input of the cooling circuit.

The movement of the worktable in the $X, Y, Z$ direction during WEDM is ensured by the use of servo drives. The path of movement of the wire electrode is also mediated by controlling the movement of the work table. Achievement of rectilinear motion or motion along a curve is ensured by controlling the different speeds of movement of the servo drives in the individual axes of the work table [Zidek 2018]. Therefore, it can be stated that the power consumption of the servo drives subsystem during WEDM depends primarily on the speed and direction of the work table movement. The speed of the work table during roughing operations is higher and contrarily, during finishing operations (offset), the speed of the work table is lower. The speed of the work table during the WEDM process also depends on the diameter of the wire electrode and the thickness of the machined material. Its value can be calculated by a mathematical model (4):

$$
E_{s u b 3}=\sum_{i=1}^{n}\left(t_{S P i} \cdot P_{S P i}\right)
$$

Where $t_{S P i}$ is the operating time of the $i$-th servo drive, $P_{S P i}$ is the power input of the $i$-th servo drive, $n$ is the number of servo drives implemented in the EDM.

Regarding the stability of the electro-erosive process, it is necessary to keep the wire electrode in motion at a certain speed. Its movement is ensured by driving the feed and winding spool using electric motors [Maščenik 2019]. In the WEDM process, the feed rate of the wire electrode is set based on its diameter, material properties, and quality requirements of the eroded area [Oniszczuk-Swiercz 2020]. To establish a mathematical notation of the electricity consumption by the wire electrode feeding subsystem, it is necessary to take into account the machining time and power input of the electric motors [Panda 2019], which ensure the rewinding of the wire tool electrode. During WEDM, it is usually a constant speed. Its speed in the machining process is set according to the quality requirements of the eroded surface. In general, a higher rewinding speed of the wire electrode is required to achieve a higher quality of the eroded surface. The purpose of setting a higher wire electrode speed during WEDM is to recover a worn wire electrode faster [Straka 2018]. The magnitude of power consumption of the wire electrode feeding subsystem during the WEDM is given by a mathematical model (5):

$$
E_{s u b 4}=\sum_{i=1}^{n}\left(t_{D M i} \cdot P_{D M i}\right)
$$

Where $t_{D M i}$ is the operating time of the $i$-th wire electrode drive mechanism, $P_{D M i}$ is the power input of the $i$-th wire electrode drive mechanism, $n$ is the number of drive mechanisms for rewinding the wire electrode.

The electrical pulse generation subsystem is the last subsystem of the electro-erosive machine. This is a relatively complicated situation for the establishment of the mathematical modeling of this subsystem power consumption. That is due to a large number of factors entering the electro-erosive process, whose parameters are constantly changing during the electro-erosive machining. In terms of power consumption, it is an extremely unstable subsystem because of the different effects of electrical parameters, workpiece material, and wire electrode, wire diameter, workpiece thickness, dielectric fluid properties, etc. [Mičietova 2013]. Moreover, the performance of the pulse system indirectly affects the current machining speed, and thus the overall power consumption during WEDM. It is therefore a relatively challenging task to explicitly establish a special mathematical model that will describe the power consumption of the electrical pulse generation subsystem. Since the amount of electrical energy consumed directly in the discharge process depends on the amount of discharge energy, which in turn is a function of MTP, of which the peak current $I(A)$, pulse on-time duration $t_{\text {on }}(\mu \mathrm{s})$ pulse off-time duration $t_{\text {off }}(\mu \mathrm{s})$ and voltage of discharge $U(V)$, has a significant effect on the amount of discharge energy, a mathematical model of the power consumption by the electrical pulse generation subsystem can be written as (6):

$$
E_{s u b 5}=\sum_{i=1}^{n}\left(t_{D E} \cdot P_{D E}\right)=f\left(I, t_{o n}, t_{o f f}, U\right)
$$

Where $t_{D E}$ is the duration of the $i$-th discharge, the $P_{D E}$ is the current value of the power of the $i$-th discharge and $n$ is the total number of discharges.

The total electricity consumption $E_{W E D M}$ during WEDM is significantly affected by the operation of individual elements of subsystems no. 1 to 5 and their current output. Therefore, the resulting mathematical model of electricity consumption during WEDM thus represents the sum of individual partial mathematical models of the considered subsystems of the EDM according to the relation (7):

$$
\begin{aligned}
& E_{W E D M}=\left(t \cdot P_{s u b 1}\right)+\left[\left(t_{f p} \cdot P_{f p}\right)+\left(t_{c s} \cdot P_{c s}\right)\right]+\left(\sum_{i=1}^{n}\left(t_{S P i} \cdot P_{S P i}\right)\right)+ \\
& +\left(\sum_{i=1}^{n}\left(t_{D M i} \cdot P_{D M i}\right)\right)+\left(f\left(I, t_{o n}, t_{o f f}, U\right)\right)
\end{aligned}
$$


The situation is clear when calculating the electricity consumption by subsystem no. 1 to 4 . Its value can be determined relatively accurately based on a monitoring system [Krenicky 2011, Murcinkova 2013], which would record the operating time of individual elements of the subsystem. The power input of the individual elements is fixed and performs as a constant in relation to the given type of electro-erosive machine. Only the operating times of individual elements of the electro-erosive machine serve as the variable in the given mathematical model [Straka 2016]. But, as it was previously mentioned, the situation concerning the determination of the electricity consumption by subsystem no. 5 is much more complicated. In addition to the variable represented by the total duration of discharges, its value is also given by the magnitude of the discharge energy. However, this discharge energy changes during the electro-erosive process and is dependent on many factors. Its exact value should therefore be determined experimentally.

\section{CONDITIONS OF EXPERIMENTS}

The value of the actual as well as the total electricity consumption through the electrical pulse generation subsystem during WEDM is primarily dependent on the amount of discharge energy. This, in turn, is given by the mutual combination of MTP, of which the peak current $I(A)$, pulse ontime duration $t_{o n}(\mu \mathrm{s})$, pulse off-time duration $t_{\text {off }}(\mu \mathrm{s})$, and voltage of discharge $U(\mathrm{~V})$ have the greatest influence. Consequently, if we want to obtain the relevant value of the electricity consumed through this subsystem, it is essential to perform experimental measurements. A standard certified power consumption measuring device can be used to measure total power consumption during WEDM. However, in this method of measurement, the total electricity consumption is recorded, including the electricity consumption by all subsystems. Therefore, if we want to obtain the amount of electricity consumed by subsystem no. 5 , it is necessary to subtract the value of consumption by subsystem no. 1 to 4 from the total consumption, based on the determined mathematical models (2) to (5).

The electro-erosive machine Agiecut Classic 3S CNC shown in the following figure 2 was used for the production of experimental samples.

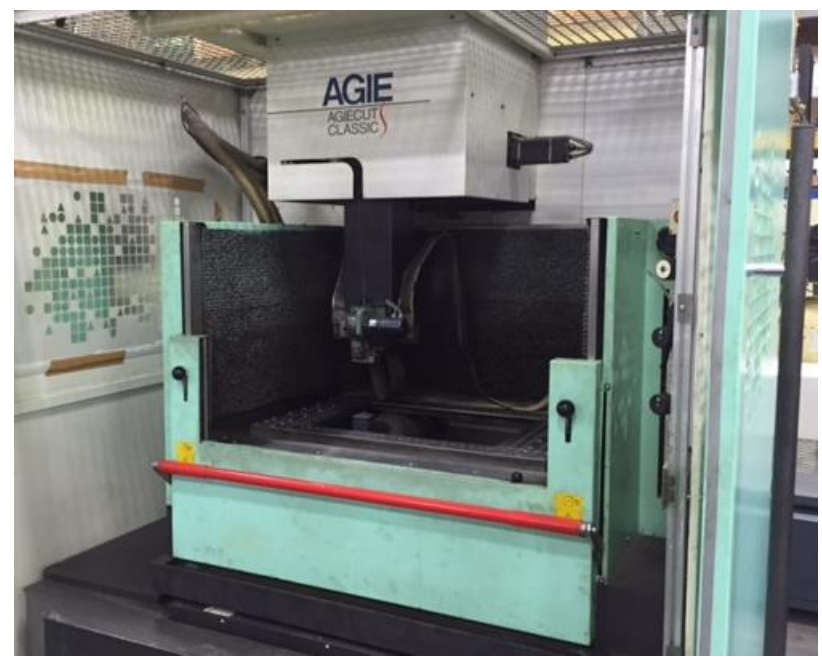

Figure 2. Electroerosive machine Agiecut Classic 3S
The following table 1 shows the basic technical parameters of the electro-erosive machine AGIE Form 30.

Table 1. Basic technical parameters of the electro-erosive machine Agiecut Classic 35

\begin{tabular}{|ll|}
\hline \multicolumn{2}{|c|}{ Technical specification } \\
\hline Max. Axis Travel $\mathrm{X} / \mathrm{Y} / \mathrm{Z}$ & $500 \times 350 \times 256 \mathrm{~mm}$ \\
\hline Max. Workpiece Size & $1050 \times 650 \times 250 \mathrm{~mm}$ \\
\hline High-speed motion & $900 \mathrm{~mm} \cdot \mathrm{min}^{-1}$ \\
\hline Wire diameter & $0.2-0.33 \mathrm{~mm}$ \\
\hline Wire speed & $60-300 \mathrm{~mm} \cdot \mathrm{s}^{-1}$ \\
\hline Rated line power & $9.7 \mathrm{~kW}$ \\
\hline Cooling system power & $1.5-6.0 \mathrm{~kW}$ \\
\hline Line voltage & $3 \times 380 \mathrm{~V} / 400 \mathrm{~V} \pm 10 \% 50 / 60 \mathrm{~Hz}$ \\
\hline
\end{tabular}

Tool steel EN 40CrMnMoS8-6 (W.-Nr. 1.2343.) was used for the production of experimental samples. It is a chromiummanganese-molybdenum steel, which is suitable for hardening in the air or in oil. This steel is characterized by very good hardenability and favorable hot strength [Botko 2019]. It is well hot-formed and, thanks to the increased sulfur content, also well machinable, both in the soft annealed state and in the refined state. It is also used for the production of less demanding tools and parts of molds for plastics processing. Figure 3 shows experimental samples made to assess the achieved quality of the machined surface in terms of surface roughness parameters and the overall economic efficiency of the WEDM process.

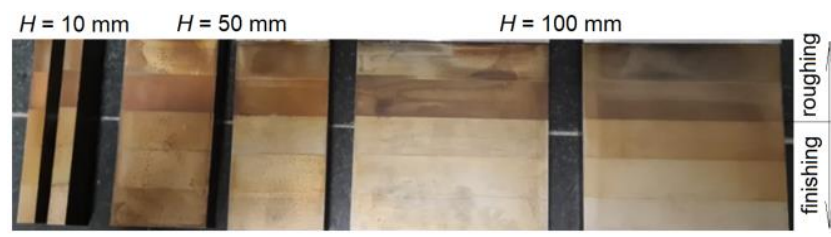

Figure 3. Experimental samples made by WEDM technology from tool steel EN 40CrMnMoS8-6 (W.-Nr. 1.2343)

Measurement of selected roughness parameters of the eroded surface of experimental samples made of tool steel EN 40CrMnMoS8-6 (W.-Nr. 1.2343) was performed using a Mitutoyo SJ 400 measuring device (Fig. 4). It is a contact measuring device with a measuring range of $1000 \mu \mathrm{m}$ and measuring accuracy of $0.01 \mu \mathrm{m}$. The measurement was performed at a length of $8 \mathrm{~mm}$.

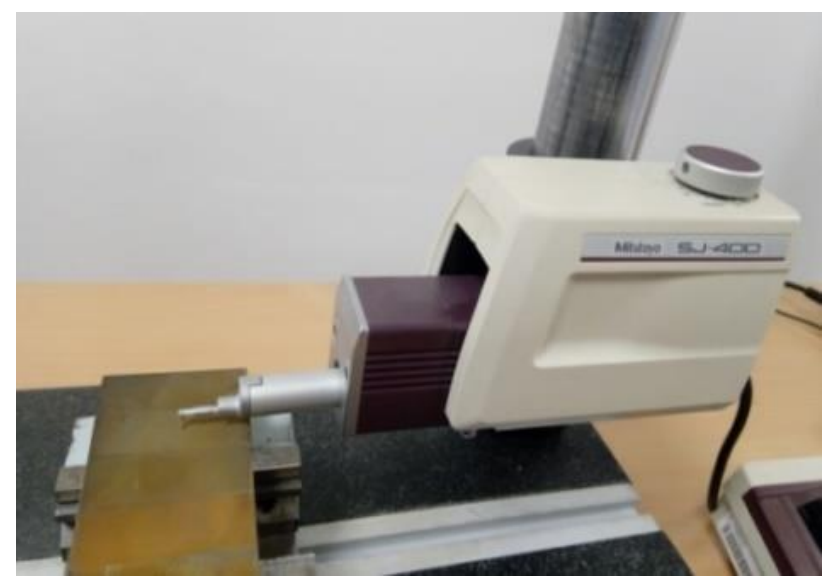

Figure 4. Measurement of selected roughness parameters of the eroded surface of the experimental samples made of tool steel EN 40CrMnMoS8-6 (W.-Nr. 1.2343) using device Mitutoyo SJ 400 
Table 2. Measured values of selected roughness parameters of eroded surface and total electricity consumption for machining a given part of the experimental sample made of tool steel EN 40CrMnMoS8-6 (W.-Nr. 1.2343)

\begin{tabular}{|c|c|c|c|c|c|c|c|c|}
\hline $\begin{array}{c}\text { Sample } \\
\text { No. }\end{array}$ & $\begin{array}{c}\text { Material } \\
\text { thickness } H \\
(\mathrm{~mm})\end{array}$ & $\begin{array}{c}\text { Operation } \\
\text { type of } \\
\text { WEDM }\end{array}$ & Performance & $\begin{array}{c}\text { Parameter } \\
R a(\mu \mathrm{m})\end{array}$ & $\begin{array}{c}\text { Parameter } \\
R \mathbf{R z}(\mu \mathrm{m}\end{array}$ & $\begin{array}{l}\text { Cutting } \\
\text { length } L \\
(\mathrm{~mm})\end{array}$ & $\begin{array}{l}\text { Machining } \\
\text { time } T(h)\end{array}$ & $\begin{array}{c}\text { Electricity } \\
\text { consumption } \\
E_{\text {WEDM }}(\mathrm{kW})\end{array}$ \\
\hline 1 & 10 & roughing & high & 2.84 & 16.81 & 15.02 & 0.12 & 0.756 \\
\hline 2 & 10 & roughing & low & 2.61 & 15.14 & 15.04 & 0.13 & 0.819 \\
\hline 3 & 10 & finishing & high & 1.25 & 7.94 & 15.01 & 0.15 & 0.878 \\
\hline 4 & 10 & finishing & low & 0.65 & 4.93 & 15.03 & 0.17 & 0.995 \\
\hline 5 & 10 & finishing & very low & 0.31 & 3.02 & 15.04 & 0.19 & 1.112 \\
\hline 6 & 50 & roughing & high & 3.04 & 18.29 & 15.04 & 0.20 & 1.440 \\
\hline 7 & 50 & roughing & low & 2.82 & 16.54 & 15.01 & 0.22 & 1.584 \\
\hline 8 & 50 & finishing & high & 1.35 & 8.89 & 15.03 & 0.27 & 1.823 \\
\hline 9 & 50 & finishing & low & 0.78 & 5.87 & 15.01 & 0.41 & 2.768 \\
\hline 10 & 50 & finishing & very low & 0.42 & 3.51 & 15.02 & 0.59 & 3.983 \\
\hline 11 & 100 & roughing & high & 3.25 & 19.58 & 15.01 & 0.29 & 2.349 \\
\hline 12 & 100 & roughing & low & 3.02 & 17.54 & 15.04 & 0.32 & 2.592 \\
\hline 13 & 100 & finishing & high & 1.58 & 10.17 & 15.02 & 0.44 & 3.366 \\
\hline 14 & 100 & finishing & low & 0.97 & 6.97 & 15.04 & 0.69 & 5.279 \\
\hline 15 & 100 & finishing & very low & 0.54 & 4.21 & 15.03 & 0.98 & 7.497 \\
\hline
\end{tabular}

Tab. 2 shows the measured values of the selected roughness parameters of the eroded surface of experimental samples made of tool steel EN 40CrMnMoS8-6 (W.-Nr. 1.2343) by WEDM technology, including the total electricity consumption needed to machine a given part of the sample.

Based on the recorded values, dependency graphs were constructed, describing the influence of the magnitude of the discharge energy and the thickness of the machined material on the roughness parameter $R a$ (Fig. $5 a$ ) and $R z$ (Fig. 5b) during WEDM of tool steel EN 40CrMnMos8-6.
Given the dependency graphs (Fig. 5ab), it can be observed that with decreasing discharge energy in both roughing and finishing WEDM operations, the value of both roughness parameters $(R a, R z)$ of the eroded surface of the samples made of tool steel EN 40CrMnMoS8-6 decreases significantly. Additionally, with an increasing thickness of the machined material at a constant value of discharge energy, the value of both roughness parameters of the eroded surface increases.

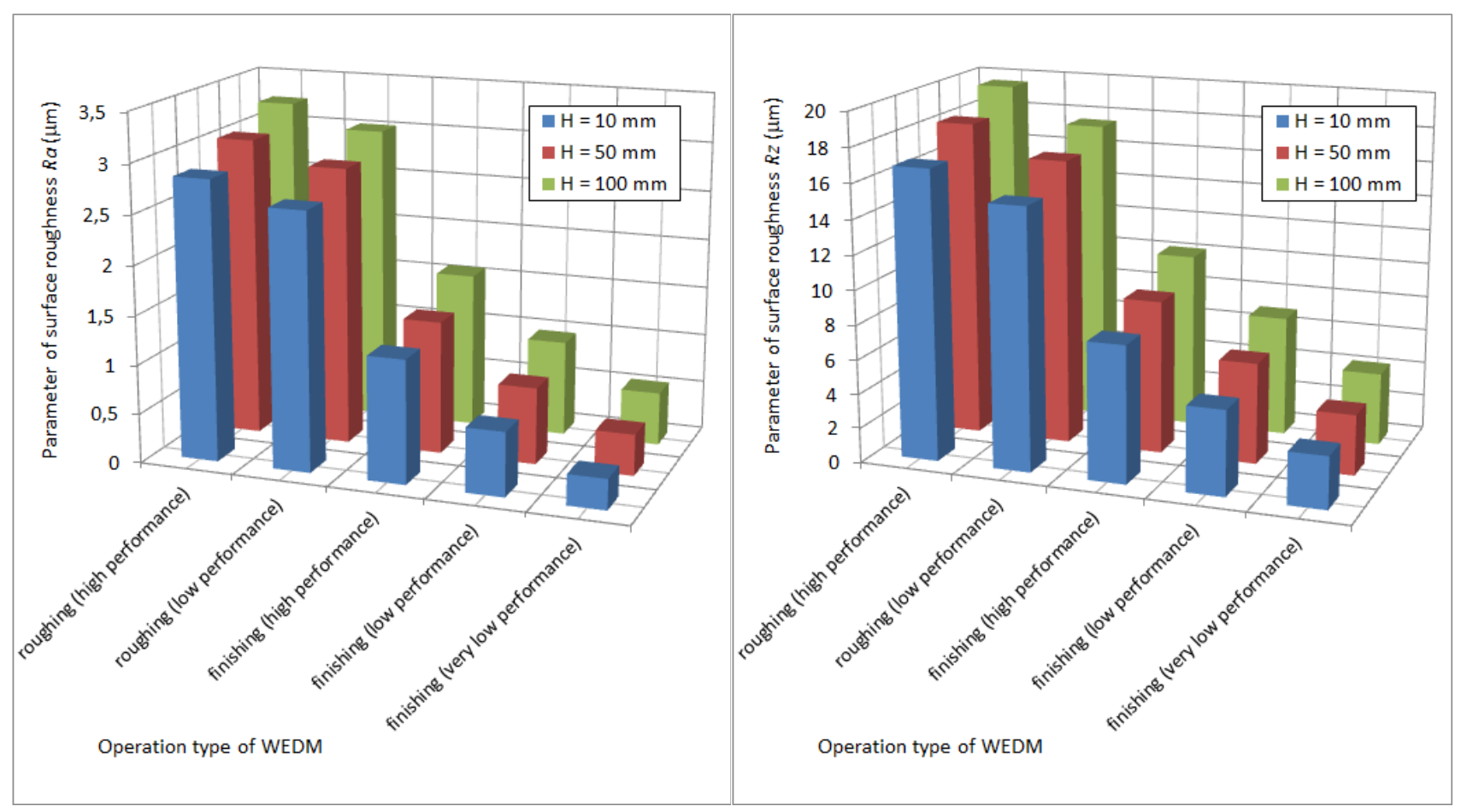

a)

b)

Figure 5. Dependence of the surface roughness parameters $R a(a)$ and $R z$ (b) on the magnitude of discharge energy and thickness of machined material during WEDM of tool steel EN 40CrMnMoS8-6 


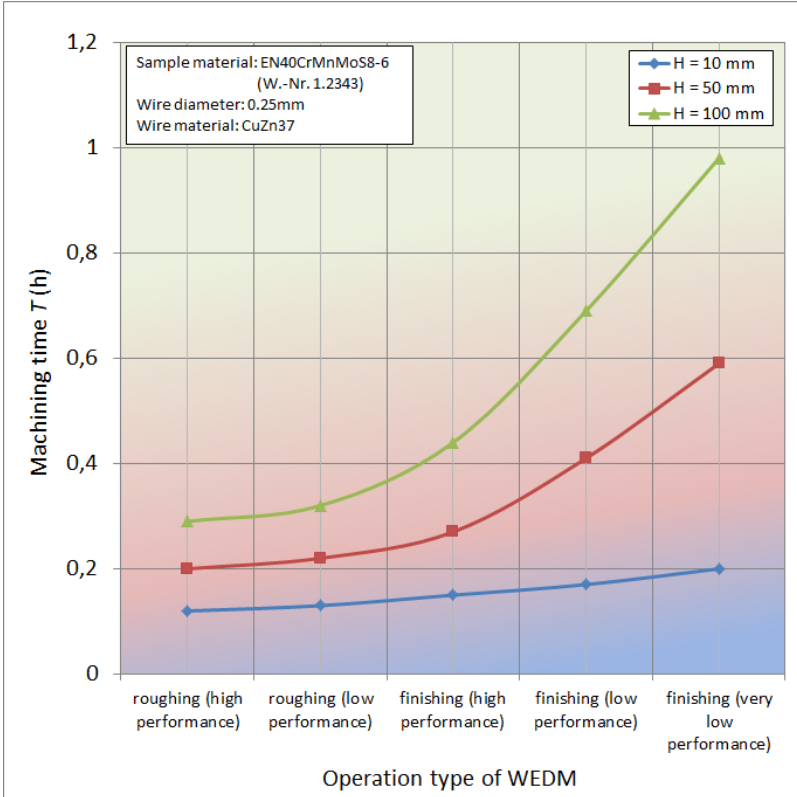

a)

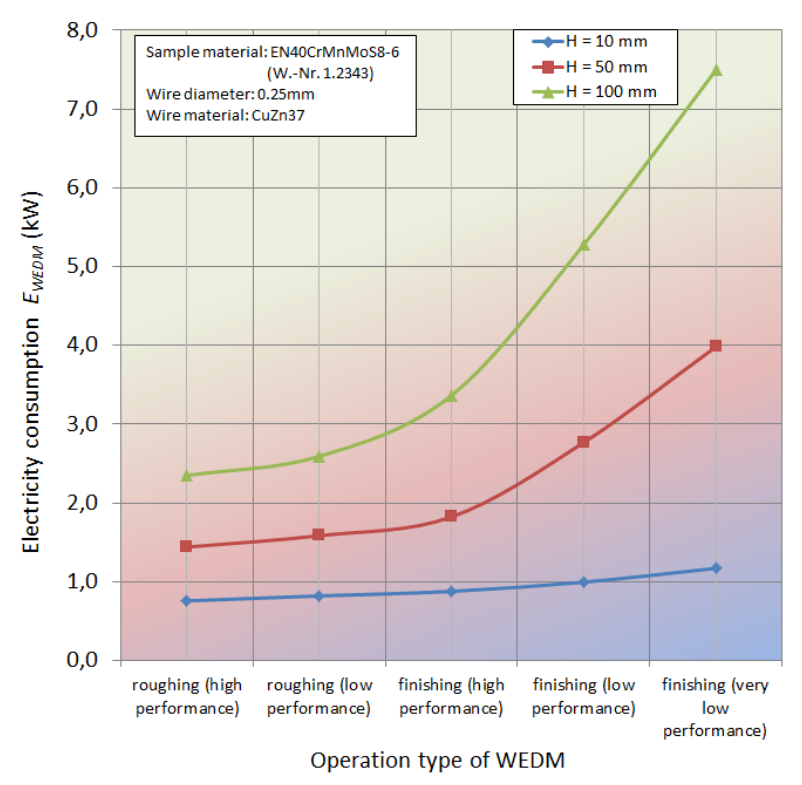

b)

Figure 6. Dependence of the machining time $T$ (a) and total power consumption $E_{\text {WEDM }}(\mathrm{b})$ on the magnitude of discharge energy and thickness of machined material during WEDM of tool steel EN 40CrMnMoS8-6

Based on the recorded values, dependency graphs were also constructed to describe the influence of the magnitude of the discharge energy and the thickness of the machined material on the value of the machining time $T$ (Fig. 6a) and electricity consumption $E_{\text {WEDM }}$ (Fig. 6b) during WEDM of tool steel EN 40CrMnMoS8-6.

Based on the given dependency graphs (Fig. 6ab) it can be stated that as the discharge energy decreases during roughing and finishing operations of the WEDM of tool steel EN 40CrMnMoS8-6., the machining time $T$ significantly increases. In addition, the total electricity consumption $E_{W E D M}$ increases as well. The same applies to the increasing thickness $H$ of the machined material.

\section{EXPERIMENTAL EXECUTION AND RESULTS}

As mentioned above, in addition to mathematical modeling, optimization is also inevitable in order to increase the economic efficiency of the WEDM process concerning the achievement of a favorable quality of the eroded surface in terms of roughness parameters [Straka 2017]. Its aim is to determine the appropriate type of discharge energy to minimize the total electricity consumption during WEDM [Straka 2020] in order to achieve the required quality of the machined surface in terms of the roughness of the eroded surface. Figure 7 shows a graphical optimization of the discharge energy with respect to the required roughness of the eroded surface Ra during WEDM of tool steel EN 40CrMnMoS86 for the range of thicknesses of the machined material $H=10$ to $100 \mathrm{~mm}$.

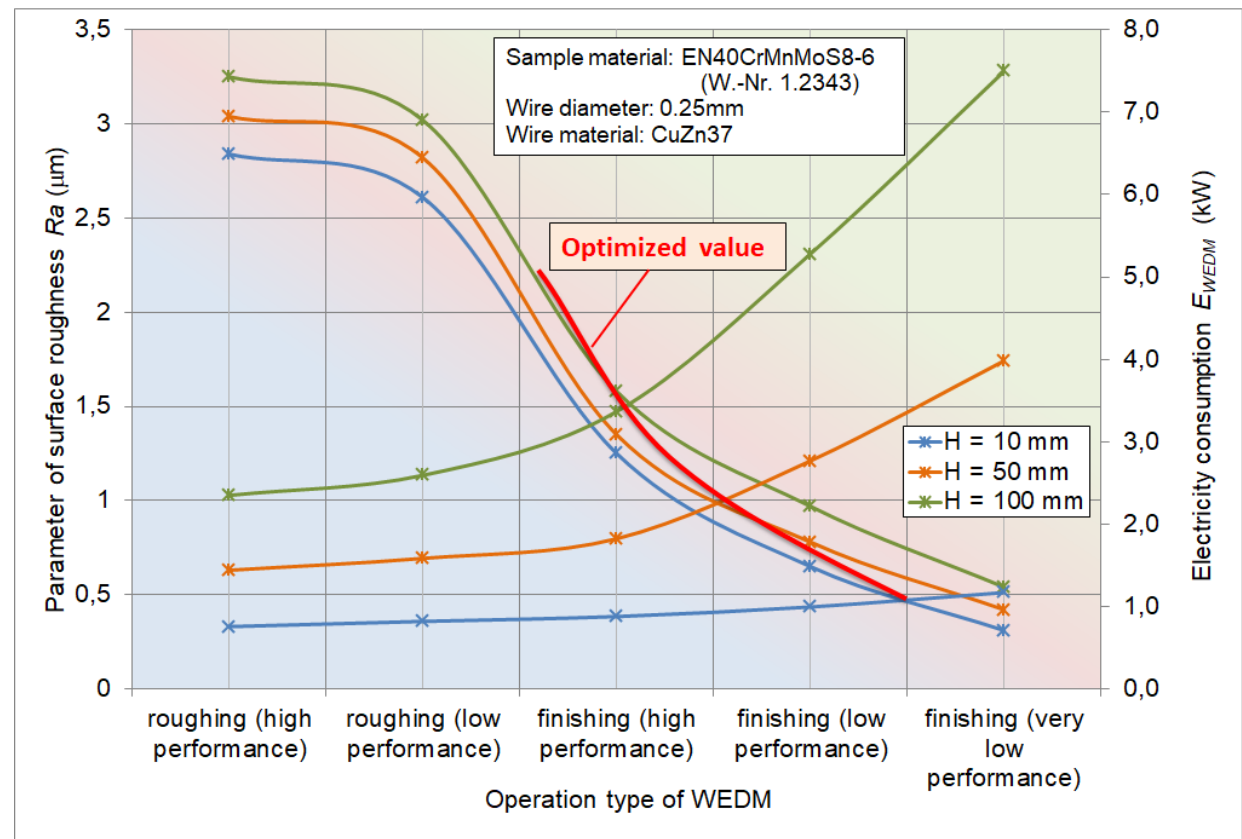

Figure 7. Optimization of discharge energy for the required roughness of the eroded surface $R a$ during WEDM of tool steel EN $40 \mathrm{CrMnMoS8-6}$ for $H$ in the range of 10 to $100 \mathrm{~mm}$ 
From the given dependency graphs (Fig. 7), it can be observed that, in terms of roughness parameters, the qualitative indicators improve with the reduction of the discharge energy by individual WEDM operations at all thicknesses $H$ of the machined material. However, in the case of the total electricity consumption EWEDM during WEDM of tool steel EN 40CrMnMoS8-6, the situation is the opposite. By reducing the discharge energy through individual WEDM operations at all thicknesses $H$ of the machined material, there is a significant increase in the total electricity consumption $E_{\text {WEDM }}$. Therefore, the performed optimization aimed to find a suitable type of WEDM operation, in which a favorable value of the roughness of the eroded surface is achieved at the same time with favorable total electricity consumption. Given the graphical optimization, it can be stated that the lowest value of the total electricity consumption is generally achieved with smaller thicknesses $H$ of the machined material and the application of high discharge energy. At a thickness of $H=10 \mathrm{~mm}$, the optimal value of $E_{\text {WEDM }}$ of approx. $1,0 \mathrm{kWh}^{-1}$ is achieved at a roughness $R a$ of the eroded surface of approximately $0.5 \mu \mathrm{m}$ by applying a finishing WEDM operation with very low discharge energy. With the thickness of the machined material $H=100 \mathrm{~mm}$, it is possible to achieve the optimal value of the total electricity consumption $E_{\text {WEDM }}$ at the roughness $R a$ of the eroded surface at the level of approximately $1.5 \mu \mathrm{m}$ with the application of WEDM finishing operation with higher discharge energy.

\section{CONCLUSIONS}

In traditional machining methods, most of the electrical energy is used to drive the spindle and also the individual portals. In WEDM, in addition to the drive of the individual portals, electrical energy is also used for rewinding the wire electrode, conditioning and supplying dielectric fluid, but especially for electric discharges, by means of which the workpiece material is partially melted and evaporated. Since during WEDM the electricity is also consumed by the electro-erosive process itself to supply electric discharges, it is apparent that as their intensity increases, so will the total electricity consumption. The increase in the intensity of electric discharges is mainly due to the power setting of the MTP. Therefore, in order to increase the economic efficiency of the WEDM process, it is necessary to focus on the strategy of controlling electricity consumption through its optimization. To better identify the partial electricity consumption, partial mathematical models were determined, on the basis of which a summary model for the calculation of the total electricity consumption at WEDM was subsequently compiled. Because of the relatively high energy intensity of the WEDM process, it is also a priority to look for suitable solutions for its optimization with regard to the achieved final quality of the eroded area. Therefore, the paper aimed to describe an empirical approach to optimizing energy efficiency during WEDM of tool steel EN 40CrMnMoS8-6 with respect to the quality of the machined surface. The obtained results revealed the relationship between the total electricity consumption and the achieved quality of the eroded area after WEDM. It was found that with the reduction of discharge energy during WEDM, the qualitative indicators of the machined surface improve in terms of roughness parameters. However, reducing the discharge energy during WEDM prolongs the machining time $T$ and increases the total electricity consumption $E_{W E D M}$ at the same time. Therefore, the task of experimental research was to find the optimal relationship between electricity consumption and the achieved quality of the eroded area after WEDM so that the results of optimization would be applicable in real conditions of technical practice.

\section{ACKNOWLEDGMENTS}

The authors would like to thank the grant agency for supporting research work the project VEGA 1/0205/19.

\section{REFERENCES}

[Antar 2011] Antar, M.T., Soo, S.L., Aspinwall, D.K., Jones, D. and Perez, R. Productivity and workpiece surface integrity when WEDM aerospace alloys using coated wires. Procedia Engineering, 2011, Vol. 19, pp. 3-8.

[Baron 2016] Baron, P., Zajac, J. and Pollak, M. The correlation of parameters measured on rotary machine after reparation of disrepair state. MM Science Journal, 2016, No. 11, pp. 12441248.

[Botko 2019] Botko, F. et al. Influence of Residual Stress Induced in Steel Material on Eddy Currents Response Parameters. Advances in Manufacturing II, Vol. 4, pp. 551-560, ISBN 978-3-030-16942-8.

[Devarajaiah 2018] Devarajaiah, D. and Muthumari, Ch. Evaluation of power consumption and MRR in WEDM of Ti$6 \mathrm{Al}-4 \mathrm{~V}$ alloy and its simultaneous optimization for sustainable production. Journal of the Brazilian Society of Mechanical Sciences and Engineering, 2018, Vol. 40, Art. No. 400.

[Gamage 2017] Gamage, J.R., DeSilva, A.K.M., Chantzis, D. and Antar, M. Sustainable machining: Process energy optimisation of wire electrodischarge machining of Inconel and titanium superalloys. Journal of Cleaner Production, 2017, Vol. 164, pp. 642-651.

[Gangil 2017] Gangil, M., Pradhan, M.K. and Purohit, R. Review on modelling and optimization of electrical discharge machining process using modern Techniques. Materials today, 2017, Vol. 4, No. 2, pp. 2048-2057.

[Hasova 2016] Hasova, S. and Straka, L. Design and verification of software for simulation of selected quality indicators of machined surface after WEDM. Academic Journal of Manufacturing Engineering, 2016, Vol. 14, No. 2, pp. 13-20.

[Krenicky 2011] Krenicky, T. Implementation of Virtual Instrumentation for Machinery Monitoring. In: Operation and Diagnostics of Machines and Production Systems, Lüdenscheid, RAM-Verlag, 2011, pp. 5-8.

[Kumar 2017] Kumar, R.A., Saurav, D., Bibhuti, B.B. and Siba, S.M. Machining performance optimization for electro-discharge machining of Inconel 601, 625, 718 and 825: an integrated optimization route combining satisfaction function, fuzzy inference system and Taguchi approach. Journal of the Brazilian Society of Mechanical Sciences and Engineering, 2017, Vol. 39, pp. 3499-3527.

[Li 2015] Li, W. and Kara, S. Characterising energy efficiency of electrical discharge machining (EDM) processes. Procedia CIRP, 2015, Vol. 29, pp. 263-268

[Mascenik 2019] Mascenik, J. Implementation of the designed program for calculation and check of chain gears. MM Science Journal, vol. 2019, No. 12, pp. 3431-3434.

[Malega 2017] Malega, P. Simulation of production systems as the effective tool of efficiency increasing. Interdisciplinarity in Theory and Practice, 2017, Vol. 12, pp. 17-22.

[Meshram 2020] Meshram, D.B. and Puri, Y.M. Optimized curved electrical discharge machining-based curvature channel. Journal of the Brazilian Society of Mechanical Sciences and Engineering, 2020, Vol. 42, No. 2, Art. No. 82.

[Michalik 2016] Michalik, P., Zajac, J., Hatala, M., Duplak, J. and Mital, D. Comparison of programming production of thin walled 
parts using different CAM systems. MM Science Journal, 2016, Vol. 10, pp. 1056-1059.

[Micietova 2013] Micietova, A., Neslusan, M. and Cillikova, M. Influence of surface geometry and structure after nonconventional methods of parting on the following milling operations. Manufacturing Technology, 2013, Vol. 13, pp. 199204.

[Mouralova 2016] Mouralova, K., Zahradnicek, R. and Houska, P. Evaluation of surface quality of $\mathrm{X} 210 \mathrm{Cr} 12$ steel for forming tools machined by WEDM. MM Science Journal, 2016, Vol. 2016, No. 5, pp. 1366-1369.

[Murcinkova 2013] Murcinkova, Z., Krenicky, T. Implementation of virtual instrumentation for multiparametric technical system monitoring. In: SGEM 2013: 13th Int. Multidisciplinary Sci. Geoconf. Vol. 1: 16-22 June, 2013, Albena, Bulgaria. Sofia: STEF92 Technology, 2013, pp. 139-144. ISBN 978-954-91818-9-0.

[Ngocpi 2020] Ngocpi, V. et al. Multi-objective optimization of PMEDM process parameters for processing cylindrical shaped parts using taguchi method and grey relational analysis. International Journal of Mechanical and Production Engineering Research and Development, 2020, Vol. 10, No. 2, pp. 669-678. [Oniszczuk-Swiercz 2020] Oniszczuk-Swiercz, D., Swiercz, R., Chmielewski, T. and Salacinski, T. Experimental investigation of influence WEDM parameters on surface roughness and flatness deviation. METAL 2020, 29th International Conference on Metallurgy and Materials, Brno, 2020, Vol. 29, pp. 611-617. [Panda 2018] Panda, A., Olejarova, S., Valicek, J. and Harnicarova M. Monitoring of the condition of turning machine bearing housing through vibrations. The Int. J. of Advanced Manuf. Technology, 2018, Vol. 97, Issue 1-4, pp. 401-411.

[Panda 2019] Panda, A., Nahornyi, V., Pandova, I., Harnicarova, M., Kusnerova, M., Valicek, J. and Kmec, J. Development of the method for predicting the resource of mechanical systems. The Int. J. of Advanced Manuf. Technology, 2019, Vol. 105, Issue 14, pp. 1563-1571.

[Raksiri 2010] Raksiri, Ch. and Chatchaikulsiri, P. CNC Wire-Cut Parameter Optimized Determination of the Stair Shape Workpiece. International Journal of Mechanical and Mechatronics Engineering, 2010, Vol. 4, No. 10, pp. 924-929.

[Rouniyar 2019] Rouniyar, A.K. and Shandilya, P. Fabrication and experimental investigation of magnetic field assisted powder mixed electrical discharge machining on machining of aluminum 6061 alloy. Proceedings of the institution of mechanical engineers part B-Journal of Engineering Manufacture, 2019, Vol. 233, No. 12, pp. 2283-2291.

[Salcedo 2017] Salcedo, A.T., Arbizu, P.I. and Perez, C.J.L. Analytical modelling of energy density and optimization of the
EDM machining parameters of inconel 600. Metals, 2017, Vol. 7, No. 5, pp. 166.

[Straka 2016] Straka, L. and Hasova, S. Assessing the influence of technological parameters on the surface quality of steel MS1 after WEDM. MM Science Journal, 2016, Vol. 11, pp. 11941200.

[Straka 2017] Straka, L., Corny, I., Pitel, J. and Hasova, S. Statistical Approach to Optimize the Process Parameters of HAZ of Tool Steel EN X32CrMoV12-28 after Die-Sinking EDM with SF-Cu Electrode. Metals, 2017, Vol. 7, No. 2, pp. 1-22.

[Straka 2018] Straka, L. and Hasova, S. Optimization of material removal rate and tool wear rate of $\mathrm{Cu}$ electrode in die-sinking EDM of tool steel. Int. J. of Advanced Manuf. Technology, 2018, Vol. 97, Issue 5-8, pp. 2647-2654.

[Straka 2020] Straka, L. and Dittrich, G. Influence of tool steel properties on surface quality after electrical discharge machining by wire electrode. Int. J. of Advanced Manuf. Technology, 2020, Vol. 106, No. 5-6, pp. 1617-1632.

[Van 2020] Van, D.N., Van, B.P. and Huu, P.N. Application of Deng's similarity-based analytic hierarchy process approach in parametric optimization of the electrical discharge machining process of SDK11 die steel. Transact. of the Canadian Society for Mech. Engineering, 2020, Vol. 44, No. 2, pp. 294-310.

[Wang 2014] Wang, Q., Liu, F. and Wang, X. Multi-objective optimization of machining parameters considering energy consumption. The International Journal of Advanced Manufacturing Technology, 2014, Vol. 71, pp. 1133-1142.

[Yaman 2020] Yaman, S. and Cakir, O. Investigation of the effects of EDM parameters on surface roughness. Journal of Advances in Manuf. Engineering, 2020, Vol. 1, No. 2, pp. 46-55. [Zhang 2017] Zhang, W. and Wang, X. Simulation of the inventory cost for rotable spare with fleet size impact. Academic Journal of Manufacturing Engineering, 2017, Vol. 15, No. 4, pp. 124-132.

[Zheng 2019a] Zheng, J., Lai, X., Zhou, X., Chen, A. and Zheng, $W$. Non-pulsed energy modeling based on energy consumption subunits in Wire Electrical Discharge Machining (WEDM) process. International Journal of Precision Engineering and Manufacturing, 2019, Vol. 20, pp. 853-862.

[Zheng 2019b] Zheng, J., Lai, X., Zhou, X., Chen, A. and Zheng, $W$. Energy modeling and minimizing energy consumption control strategy of wire electrical discharge machining (WEDM) through electrical parameters. The International Journal of Advanced Manuf. Technology, 2019, Vol. 103, pp. 4341-4353. [Zidek 2018] Zidek, K., Vasek, V., Pitel, J. and Hosovsky, A. Auxiliary device for accurate measurement by the smartvision system. MM Science Journal, 2018, No. March, pp. 2136-2139.

\section{CONTACTS}

assoc. prof. Ing. Luboslav Straka,PhD.; Ing. Patrik Kuchta Department of Automotive and Manufacturing Technologies Faculty of Manufacturing Technologies of the Technical University of Kosice with a seat in Presov, Sturova 31, 08001 Presov, Slovakia, tel.:+421 556026365

e-mail: luboslav.straka@tuke.sk, patrik.kuchta@tuke.sk 